\title{
ACONDICIONAMIENTO IDIOCINÉTICO Y EL CARNAVAL DE ICHU - PUNO
}

\author{
Idiocinetic Conditioning and Ichu Carnival - Puno
}

\author{
Irene Benita Gil Quispe ${ }^{1}$
}

\begin{abstract}
RESUMEN
Las manifestaciones dancísticas autóctonas de la región Puno son variadas, destacando las danzas de carnaval, ejecutadas intuitivamente, carentes de técnica; se analizó e interpretó los movimientos corporales del carnaval de Ichu, y su aplicación de técnica clásica. En tal sentido, el acondicionamiento cuerpo - mente, proceso de visualización e integración de conciencia y control (ideocinética) se enmarca en la metodología de la investigación cualitativa. Además, se determina que la práctica de técnica clásica conduce al logro de una mayor calidad en la ejecución de los movimientos corporales.
\end{abstract}

Palabras clave: Idiocinética, danza, técnica clásica, carnavales.

\section{ABSTRACT}

Native dancistic manifestations of the Puno region are varied, highlighting the carnival dances, performed intuitively, lacking of technique; the body movements of Ichu Carnaval and their application in classic techniques were analyzed and interpreted. In this sense the body-mind conditioning, visualization and awarenes sintegration and control (ideocinetic) is part of the methodology of qualitative research. In addition, it is determined that the practice of classical technique leads to achieve higher quality in the execution of body movements.

Keywords: Idiocinetic, dance, classical technique, carnivals.

\section{INTRODUCCIÓN}

El carnaval de Ichu es una danza autóctona de la provincia de Puno, que ha llamado la atención de investigadores como Cuentas Ormachea (1956), Cuentas Gamarra (1983), Barrionuevo (1989), del Gobierno Regional de Puno (2005), Valencia (2007), Palacios (2009), entre otros. La carencia de análisis coreográficos, motivaron la presente investigación que analizó e interpretó las técnicas de preparación corporal del carnaval de Ichu, mediante la técnica de acondicionamiento cuerpo-mente, la visualización e integración de imágenes, conciencia y control, en la preparación de las danzas. La visualización ideocinética, conocida también como ideocinésis, es desarrollada con el objetivo de utilizar ciertas imágenes para crear una mejor coordinación neuromuscular, que ayude al danzante a mejorar el alineamiento y el equilibrio de la acción de los

\footnotetext{
${ }^{1}$ Magister en Arte, Licenciada en Arte. Docente de la Facultad de Ciencias Sociales de la Universidad Nacional del Altiplano. Puno-Perú.

Correo electrónico: igilquispe@yahoo.com
} 
músculos que rodean las articulaciones. El ensayo cognitivo de una acción sin la puesta en práctica de movimientos físicos realizado inicialmente en reposo hasta la actividad progresiva, permite el logro de una mayor calidad en la ejecución de los movimientos corporales.

\section{REGISTRO DEL CARNAVAL DE ICHU}

Nuestras observaciones del Carnaval de Ichu vienen del 2014, realizado en el centro poblado Ichu, provincia de Puno.

En base a los registros audiovisuales del carnaval de Ichu, precisamos sus movimientos corporales:

\section{Posiciones iniciales}

Cabeza. Mujer: ligeramente inclinada hacia adelante, mirada hacia el piso. Varón: cabeza dirigida hacia arriba y la mirada hacia el horizonte.

Brazos. Mujeres: ambos brazos relajados hacia el piso y desde el codo doblan los antebrazos oblicuamente hacia arriba. Cada mano sostiene una kollacha que posteriormente se bate en círculos alternos, tres vueltas hacia adelante y tres hacia atrás. Varones: posiciones iniciales similares con la diferencia en la extensión de los brazos y antebrazos, el batido es idéntico.

Piernas, se encuentran separada a una distancia aproximada de $15 \mathrm{~cm}$ y plenamente apoyados al piso, dirigidos hacia adelante. Seguidamente levantan las piernas alternadamente, iniciándose el

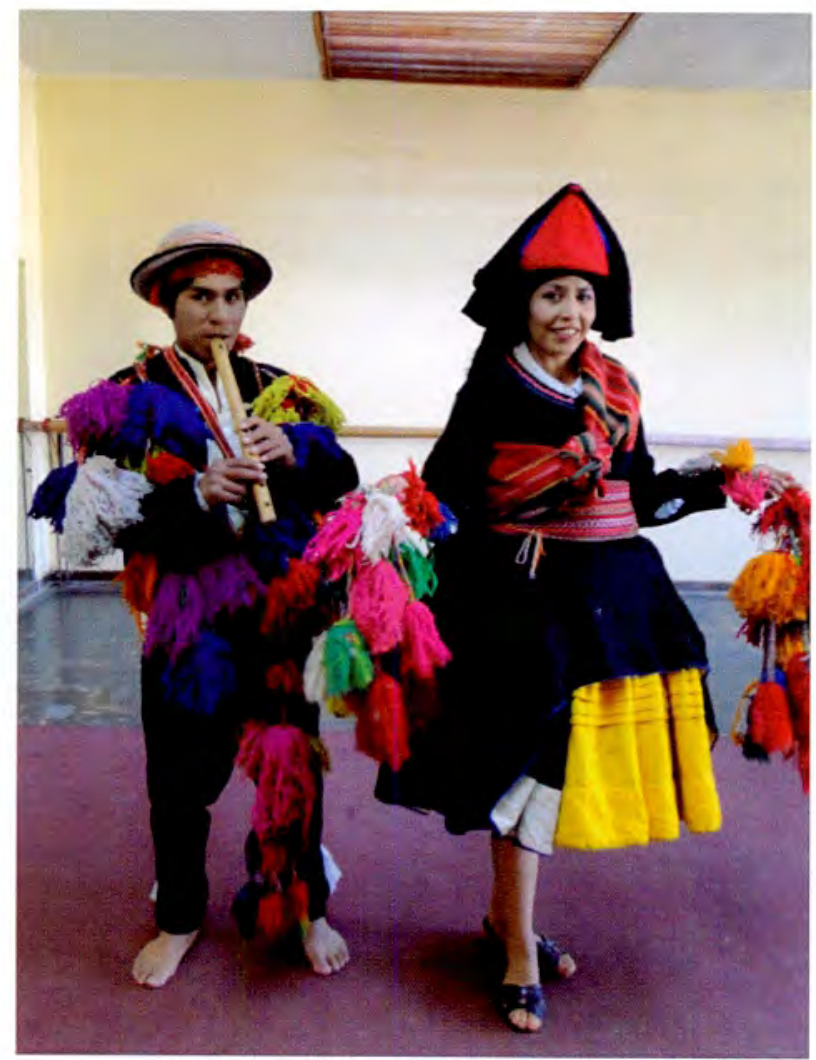

Figura 1. Pareja de danzantes del carnaval de Ichu 
movimiento con la pierna derecha, levantando el muslo y doblando la rodilla hacia abajo. La pierna izquierda sostiene el cuerpo presto a levantarla cuando el derecho retorna a su posición inicial, y así continúa con el izquierdo y derecho, a aproximadamente 10 centímetros del piso.

Torso, de la mujer ligeramente inclinada hacia adelante; del varón, ligeramente inclinado hacia atrás.

\section{Las piernas}

$1^{\circ}$ Etapa. Mujeres avanzan hacia adelante con pasos a ritmo moderado; iniciando el movimiento con la pierna derecha, arqueando desde la rodilla hacia abajo. Pisa a unos aproximados $25 \mathrm{~cm}$ de distancia de la pierna izquierda, que sostiene el cuerpo con medio pie, preparándose para levantar cuando el pie derecho impacta en el suelo, de igual forma la pierna izquierda se levanta y avanza $20 \mathrm{~cm}$ de distancia, sucesivamente.

El varón: efectúa con mayor intensidad el paso, hacia adelante es más largo, unos $35 \mathrm{~cm}$ y de $30 \mathrm{~cm}$ con relación al piso.

$2^{\circ}$ Etapa. Es similar a la etapa anterior en el avance y la forma de los pasos, en este caso avanza 3 pasos largos y retroceden tres pasos cortos y así sucesivamente, de esta forma avanza hacia adelante y realiza otros pasos. En las mujeres los pasos tienen una distancia de $25 \mathrm{~cm}$ de pie a pie y de 20 $\mathrm{cm}$ aproximadamente con relación al piso. En los varones persiste el movimiento del paso de unos 35 o $30 \mathrm{~cm}$ con relación al piso.

$3^{\circ}$ Etapa. Inicialmente se encuentran las piernas paralelas con los pies dirigidos hacia adelante, separadas unos 20 $\mathrm{cm}$. Empieza el movimiento la pierna derecha ejecutando 2 pasos laterales a su costado, la pierna izquierda sirve de apoyo y avanza dos pasos. En el retorno, la misma pierna izquierda avanza 3 pasos lateralmente, mientras que la pierna derecha también retorna lateralmente como apoyo dando 3 pasos. El retorno se da de la misma manera.

En otro momento, este paso lo ejecutan en zigzag, avanzan 3 pasos en diagonal derecha hacia adelante, luego retornan en diagonal izquierda 3 pasos hacia adelante, así sucesivamente van avanzando en zigzag.

En los varones se incrementa la intensidad de los movimientos, los pasos son más largos y la altura del piso al pie levantado es ligeramente más alta. En los pasos laterales o laterales diagonales en zigzag hay otras variaciones, pues los danzantes ejecutan 5 y 7 pasos laterales a la derecha y retornan en igual número de pasos. Si el avance de la coreografía es en zigzag, también los pasos son en diagonal.

En los varones la distancia de los pasos es más amplia y los pies se elevan mucho más que las mujeres.

$4^{\circ}$ Etapa. En esta fase en el grupo de danzarines se entrelazan varones y mujeres. Las mujeres agarradas entre sí mediante sus kollachas. Los varones también agarrados a través de sus kollachas. Posteriormente la fila de mujeres entrecruzan los brazos con la fila de varones. Avanzan grupalmente en línea 20 pasos hacia adelante y luego retornan 20 pasos. Los pasos hacia adelante son más largos y los pasos hacia atrás son más cortos. Damas y varones dan los mismos pasos.

\section{Los brazos}

$1^{\circ}$ Etapa. Inicialmente tanto mujeres como varones, sostienen con ambas 
manos las kollachas abultadas, de los hombros hasta los codos tienen caída vertical. Los antebrazos se doblan haciendo un ángulo de 90 grados de abertura, y la dirección de las manos es a los laterales respectivos. Luego, con ambas manos baten las kollachas en forma de círculos, primero con dirección hacia adelante, después de 3 movimientos, cambian la dirección del batido hacia atrás.

Cuando las mujeres avanzan, ligeramente inclinan el tórax hacia adelante, por lo tanto el brazo gira hacia la parte posterior, siempre con los batidos constantes.

$2^{\circ}$ Etapa. Cuando los danzantes hacen movimientos en giros, la posición de los brazos es distinta. Si el giro es al lado izquierdo, el brazo derecho se eleva hacia arriba en curva, y por encima de la cabeza, batiendo la kollacha en círculo. En cambio el brazo izquierdo se extiende hacia el suelo, en curva y hacia atrás, manteniendo el batido de la kollacha en forma de círculo.

Cuando el danzante completa el giro, se retorna girando hacia el otro lado y lentamente. Este movimiento es similar en damas y varones.

$3^{\circ}$ Etapa. En los giros con pareja, se entrelazan los brazos doblados desde el codo. La pareja está frente a frente. El varón ofrece el brazo derecho doblado a la mujer. Ella entrelaza también el brazo doblándo hacia su tórax. Luego la pareja hace el giro respectivo sin soltarse. Después de completar el círculo los que ejecutan la danza, cambian inmediatamente de brazos, entrelazan los brazos izquierdos y giran en sentido contrario. $\mathrm{Al}$ final intensifican los pasos y el giro en un círculo es mucho más amplio. Aquí los brazos de la mujer y el varón deben tener bastante resistencia para evitar soltarse. $4^{\circ}$ Etapa. El movimiento en grupo es similar en mujeres y varones. Generalmente forman una fila de 10 danzarines agarrados de sus kollachas y continúan alternando los movimientos de los brazos. Los varones realizan con mayor fuerza los movimientos rítmicos.

\section{Torso}

$1^{\circ}$ Etapa. Cuando avanzan las mujeres, inclinan el tórax hacia adelante y cuando retroceden inclinan hacia atrás. En los varones se aprecia mayor intensidad en los dos movimientos.

$2^{\circ}$ Etapa. En los giros individuales las mujeres realizan los siguientes movimientos: si el giro es al lado izquierdo, sigue la línea de los hombros, el hombro derecho se levanta hacia arriba y el hombro izquierdo se baja doblando hacia atrás. En el cambio de giro, el hombro izquierdo sube arriba y el hombro derecho baja. Este movimiento se va alternando sucesivamente. En los varones se repite esta secuencia, pero es ligeramente más rápido.

$3^{\circ}$ Etapa. En los giros con pareja, ambos deben seguir la línea de los hombros, inclinando hacia el lado lateral del brazo entrelazado, en el cambio de giro se inclina al otro lado. De esta manera se va repitiendo una y otra vez hasta el cambio del tono de la música.

$4^{\circ}$ Etapa. En los movimientos y desplazamientos grupales, mujeres y varones avanzan con el tórax inclinado hacia atrás.

\section{Los saltos.}

$1^{\circ}$ Etapa. Los danzantes inician los saltos hacía adelante con la pierna derecha, mientras que la pierna izquierda impulsa el cuerpo dando 2 toques en el piso. Cuando la pierna derecha hace contacto con el piso, luego del 
salto, la izquierda se eleva en arco dando el salto repetitivo, el pie derecho a su vez impulsa en dos movimientos. Así continúa alternadamente.

En las mujeres la altura del pie levantado desde el piso, es de $30 \mathrm{~cm}$ y en los varones es de $40 \mathrm{~cm}$ aproximadamente. La distancia de pierna a pierna es de $40 \mathrm{~cm}$ en las damas y en los varones $50 \mathrm{~cm}$.

En este mismo movimiento los danzantes ejecutan 3 saltos hacia adelante y 3 saltos hacia atrás.

$2^{\circ}$ Etapa. En los saltos en zigzag, los realizan en diagonal. Inicialmente dan 3 saltos en diagonal derecho, luego dan otros tres saltos en diagonal izquierdo, así van avanzando hacia adelante en zigzag. En el desarrollo de los pasos llegan a dar 7 saltos en cada diagonal.

$3^{\circ}$ Etapa. Los saltos laterales se inician con la pierna derecha doblada hacia abajo, mientras que la pierna izquierda sirve como soporte e impulsa con 2 movimientos cuando la pierna derecha pisa firme. Inmediatamente la pierna izquierda se levanta para el salto, sostenido e impulsando por la derecha. También se despliegan dando 5, 6 y 7 saltos laterales, para luego retornar con la misma cantidad de saltos.

\section{Los giros}

$1^{\circ}$ Etapa. Los que danzan ejecutan una vuelta completa en un mismo sitio, diseñando su proyección en un círculo. Inician el paso con la pierna derecha que gira por adelante, dando un apoyo en el piso a $180^{\circ}$ y con el siguiente paso completa los otros $180^{\circ}$ del círculo. La pierna derecha tiene que ejecutar 2 pasos amplios en el giro, en cambio la pierna izquierda 2 pasos cortos, en el mismo sitio y luego se cambia de posición por el giro del cuerpo. El retorno es al revés, la pierna izquierda se mueve con 2 pasos amplios y la derecha con 2 pasos cortos. Estos giros son idénticos tanto en mujeres como en varones.

$2^{\circ}$ Etapa. Giran avanzando hacia adelante, dando 3 pasos en un semicírculo largo, luego con 2 pasos cierran el giro. Los tres primeros pasos son largos y los otros dos cortos. El retorno es similar, solo cambiando el movimiento de las piernas.

En mujeres y varones las formas y extensiones de los pasos son idénticas.

$3^{\circ}$ Etapa. En esta fase las parejas giran, pero con los brazos entrelazados y doblando los codos y cada uno de los danzantes estira para su lado y de esta manera ambos brazos quedan bastante tensados y no deben soltarse.

Posteriormente, se inicia el giro en un círculo más amplio, trotando con varios pasos hasta completar el círculo. Luego este movimiento se invierte, cambiando el movimiento de los brazos entrelazados y giran en sentido contrario dando hasta 7 pasos cada uno.

Hay momentos en que se incrementa la intensidad de los pasos y movimientos y los danzarines parecen correr. De esta manera los giros y movimiento se hacen mucho más rápido. En esta posición, se corre el riesgo de perder la armonía de la dan$\mathrm{za}$, es por ello que tiene que ser bien ejecutado y los ensayos son importantes para no cometer errores.

El análisis de los movimientos corporales, cabeza, torso, brazos, piernas, saltos y giros nos permiten establecer sus movimientos. (Tabla 1).

Los movimientos corporales del carnaval de Ichu guardan similitudes y afinidades con la técnica clásica, permitiendo aplicar criterios y principios de 
acondicionamiento ideocinético, coordinación neuromuscular que busca un mejor alineamiento, equilibrio de acción muscular alrededor de las articulaciones. (Tabla 2).

La aplicación del acondicionamiento ideocinético a 20 parejas danzantes del carnaval de Ichu, permitió determinar que las actividades como conciencia y control facilitan la aplicación de la técnica clásica; no así las actividades referentes al poder de las imágenes, estimulación mental del movimiento, aplicación de la imagen, desarrollo de las imágenes personales. (Tabla 3).

\section{LA TÉCNICA CLÁSICA Y EL CARNAVAL DEICHU}

La praxis del carnaval de Ichu, mediante el acondicionamiento corpo- ral, permitió determinar que la aplicación de los criterios genéricos de acondicionamiento, actividades como el acondicionamiento corporal completo, la carga progresiva, el principio de periodización, el precalentamiento, el reposo constructivo, propenden a la aplicación de la técnica clásica en la ejecución del carnaval de Ichu.

La técnica de "visualización mental puede definirse como «el ensayo cognitivo de una acción sin la plena actuación de los movimientos físicos implicados» [...] o como «el ensayo de una actividad física en ausencia total de cualquier movimiento muscular»" (Flanklin, 2006:19), mediante la utilización de imágenes físicas y mentales para el logro de una mejor coordinación motora que permita al danzarín mejorar el alineamiento y el equilibrio de la acción de los

Tabla 1. Movimientos corporales del carnaval de Ichu

\begin{tabular}{|c|c|c|}
\hline $\begin{array}{l}\text { Segmentos } \\
\text { corporales }\end{array}$ & Etapas & Criterios técnicos artísticos \\
\hline & Cabeza & Dirección del movimiento. \\
\hline & Brazos & Intensidad del movimiento. \\
\hline & Piernas & Extensión del movimiento. \\
\hline & Torso & Distanciamiento: - Altura \\
\hline Las piernas & En 4 etapas & $\begin{array}{l}\text {-Adelante } \\
\text {-Atrás }\end{array}$ \\
\hline Los brazos & En 4 etapas & - Laterales \\
\hline El torso & En 4 etapas & Actitud emotiva. \\
\hline Los saltos & & Similitud de movimientos de varón y mujer. \\
\hline $\begin{array}{l}\text { Los saltos } \\
\text { Los giros }\end{array}$ & En 3 etapas & Diferencias de movimiento de varón y mujer. \\
\hline Los giros & En 3 etapas & En las piernas y los brazos diferencias y similitudes del lado derecho e izquierda. \\
\hline
\end{tabular}

Fuente:I.B.G.Q

Tabla 2. Aplicación del proceso de visualización ideocinético Actividades

\section{Propósito}

Logro

a. Conciencia y control a. Propende a reemplazar al control automático por el control de conciencia. $\mathrm{Si}$ b. Lograr que la memoria registre un patrón de movimiento más eficaz. $\mathrm{Si}$

b. El poder de las imágenes

a. Aplicación de tipos selectos de visualización para mejorar la técnica de la No danza.

b. Dominio de la visualización mental como ensayo cognitivo de una

c. Estimulación mental a. Facilita la creación de imágenes vividas que incluyen las características No del movimiento. físicas del movimiento tal como se expresa en la realidad.

d. Aplicación de la a. Imaginación dinámica permanente. imagen

a. Imaginación dinámica permanente.
b. Utilización de imágenes simples y comprensibles.

e. Desarrollo de las

a. Concentración selectiva. imágenes personales $\mathrm{b}$. Utilización del tacto.

c. Ejecución del movimiento imaginario. 
Tabla 3. Acondicionamiento corporal

\begin{tabular}{|c|c|c|}
\hline Actividades & Propósito & Logro \\
\hline $\begin{array}{l}\text { a. Criterios genéricos de } \\
\text { acondicionamiento }\end{array}$ & $\begin{array}{l}\text { a. Beneficia a que la mente acompañe el cuerpo durante las prácticas } \\
\text { b. Logra la flexibilidad corporal de un modo equilibrado. }\end{array}$ & $\begin{array}{l}\text { Si } \\
\text { Si }\end{array}$ \\
\hline $\begin{array}{l}\text { b. Acondicionamiento } \\
\text { corporal completo }\end{array}$ & $\begin{array}{l}\text { a. Fortalece la presencia mental y la concentración con solidez } \\
\text { b. Disposición en los ejercicios de un dialogo continuo entre la mente y } \\
\text { elcuerpo. }\end{array}$ & $\begin{array}{c}\text { No } \\
\text { Si }\end{array}$ \\
\hline $\begin{array}{l}\text { c. El principio de } \\
\text { especificidad }\end{array}$ & $\begin{array}{l}\text { a. Selecciona ejercicios que fortalece los músculos, para logro de una } \\
\text { específica capacidad: resistencia, flexibilidad, equilibrio, velocidad, } \\
\text { con su entrenamiento. }\end{array}$ & No \\
\hline d. Carga progresiva & $\begin{array}{l}\text { a. Intensidad del trabajo. } \\
\text { b. Volumen de repeticiones. } \\
\text { c. Frecuencia de actividades. }\end{array}$ & $\begin{array}{l}\mathrm{Si} \\
\mathrm{Si} \\
\mathrm{Si}\end{array}$ \\
\hline $\begin{array}{l}\text { e. El principio de } \\
\text { periodización }\end{array}$ & $\begin{array}{l}\text { a. Fase preparatoria. } \\
\text { b. Fase de desarrollo. } \\
\text { c. Fase de mantenimiento. }\end{array}$ & $\begin{array}{l}\mathrm{Si} \\
\mathrm{Si} \\
\mathrm{Si}\end{array}$ \\
\hline f. El precalentamiento & $\begin{array}{l}\text { a. Sirve para precalentar los músculos. } \\
\text { b. Ejercicios pausados y simples para pasar a rápidos a complejos. }\end{array}$ & $\begin{array}{l}\mathrm{Si} \\
\mathrm{Si}\end{array}$ \\
\hline g. Reposo constructivo & $\begin{array}{l}\text { a. Relajación del cuerpo y estiramiento de músculos gradual. } \\
\text { b. Enfriamiento y sesión de reposo. }\end{array}$ & $\begin{array}{l}\text { Si } \\
\text { Si }\end{array}$ \\
\hline
\end{tabular}

Fuente: I.B.G.Q

músculos que rodean las articulaciones, pues "el sistema nervioso central actúa, [...], como integrador de información y generador de órdenes" (Massó, 2012, p. 126). El ejercicio realizado por 20 parejas, de conciencia y control, permitió aplicar la técnica clásica, previa a la participación en eventos de conglomerado social que "corresponden al ciclo de la naturaleza, las actividades agrícolas y humanas" (Muller, 1984, p. 167), al igual que los carnavales. En tal sentido las danzas autóctonas constituyen la expresión espontánea de la colectividad social, por eso solo busca que la memoria registre un patrón eficaz de movimiento.

De esa manera, el carnaval de Ichu, permite asimilar academicismos, por ser también una expresión cultural dinámica que "no solamente la mantienen sino que la recrean o la transmiten constantemente para dotarles a sus miembros de una cultura y de referente que les permita afirmar su identidad" (Kapsoli, 1988, p. 7), en tiempos de cambios sociales, científicos y tecnológicos, procesos que tienen efecto en la cultura en general y la cultura andina en particular.

\section{CONCLUSIÓN}

Existen similitudes y afinidades entre los movimientos corporales del carnaval de Ichu y la técnica de danza clásica.

La enseñanza de la técnica clásica basado en el acondicionamiento ideocinético permite una mayor calidad en la ejecución de los movimientos corporales del carnaval de Ichu.

\section{REFERENCIAS BIBLIOGRÁFICAS}

Cuentas Ormachea, E. (1956). Estampas puneñas - La fiesta de San Pedro de Icho. Revista del Instituto Americano de Arte. $\mathrm{N}^{\circ} 5$.

Cuentas Gamarra, L. (1983). Danzas del Altiplano. En: Álbum de Oro Monografía de departamento de Puno. Puno, Perú: Los Andes.

Barrinuevo, A. (1989). Los dioses de la lluvia. Lima, Perú: CONCYTEC.

Flanklin, E. (2006). Danza - Acondicionamiento físico. Barcelona, España: Edit. Paidotribo.

Gobierno Regional Puno. (2005). Etnodanzas. Puno, Perú: Gobierno 
Regional Puno.

Kapsoli, W. (1988). Historia y cultura andina - cuaderno de Folklore $\mathrm{N}^{\circ} 2$. Lima, Perú: Editorial del Centro de Folklore José María Arguedas.

Massó, N. (2012). El Cuerpo en la Danza. Barcelona, España: Edit. Paidotribo.

Muller, T. \& Helga. (1984). Cosmovisión y celebraciones del mundo andi- no. Allpanchis $\mathrm{N}^{\circ} 23$. Año XIV, vol. XX. Cusco, Perú: Edit. Instituto de Pastoral Andina.

Palacios, V. (2009). Catálogo de la música tradicional de Puno. Tomo II. Lima, Perú: Fondo Editorial del Congreso del Perú.

Valencia, A. (2007). Danzas autóctonas de Puno. Puno, Perú: Gobierno Regional Puno. 